\title{
TRENDS AND INFLUENCING FACTORS REGARDING THE INCIDENCE OF BRAIN METASTASES IN VARNA AND DOBRITCH REGION
}

\author{
Peev N. A., S. T. Dyankov, Sv. Kalevski, R. Nedelkov \\ Sector Neurosurgery, Medical University - Varna, Department of Neurosurgery, \\ ENT and Ophthalmology, Neurosurgical Clinic, "St. Anna" District Hospital
}

Reviewed by: Assoc. Prof. N. Deleva

\section{SUMMARY}

\begin{abstract}
According the data published for 2005 year by World Health Organization (WHO), Among 58 million dead outcomes worldwide, 7.6 million are due to malignant neoplastic diseases. By the prognosis of WHO, for 2015 year we should expect 9 million dead outcomes due to malignancies, for 2020 WHO predicts 10,3 million and for 2030 - 11,4 million. Investigations for Bulgaria, in accordance with the prognoses of WHO, show marked tendency toward significant increase of the incidence of the malignancies. In the present study we collected and evaluated statistical information for the patients diagnosed with malignancies in Varna and Dobritch region for a period 1983 - 2006. For the period 1993 - 2006 we collected and evaluated statistical information for the patients with brain metastases (BMs) and primary brain tumors, admitted in the Neurosurgical Clinic of "St. Anna" District Hospital of Varna. Based on the data analysis from the available publications concerning the problem BMs, also the data acquired in our investigation we conclude that, despite the tremendous advancement of the modern medicine, the number of the patients with malignant diseases, also patients in the final IV stage (TNM) constantly and steady increases. The majority of the patients in IV TNM stage suffer from neurologic complications that are primarily attributable to BMs
\end{abstract}

Key words: brain, metastases, incidence, prognosis, malignant

\section{INTRODUCTION}

According the data published for 2005 year by World Health Organization (WHO), among 58 million dead outcomes worldwide, 7.6 million are due to malignant neoplastic diseases. Thus they follow as a third leading cause for dead outcome $(44,43)$. By the prognosis of WHO, for 2015 year we should expect 9 million dead outcomes due to malignancies, for $2020 \mathrm{WHO}$ predicts 10,3 million and for 2030 - 11,4 million. WHO also predicts that the newly diagnosed cases with malignant neoplastic diseases will increase with $50 \%$ from 10,9 million in 2002 to 16 million in 2020 (43).

Investigations for Bulgaria (13), in accordance with the prognoses of WHO show marked tendency toward significant increase of the incidence of the malignancies - for the period 2012 - 2017 the anticipated incidence of lung cancer is $43 \%$ higher if compare with the period 1998 - 2002, for breast cancer the anticipated growth is $40 \%$, for prostate cancer - $30 \%$, for uterine neck cancer - $25 \%$.

Address for correspondence:

N. Peev, Dept. of Neurosurgery, Medical University of Varna,

55 Marin Drinov str., BG-9002, Varna

e-mail: nikolay.a.peev@gmail.com

\section{MATERIAL AND METHODS}

In the present study we collected and evaluated statistical information for the patients diagnosed with malignancies in Varna and Dobritch region for the period 1983 - 2006. The Data presented on Figure 1 gives information for the yearly distribution of the all registered patients with malignancies, also the patients at the final IV TNM stage.

For the period 1993 - 2006 we collected and evaluated statistical information for the patients with brain metastases (BMs) and primary brain tumors, admitted in the Neurosurgical Clinic of "St. Anna" District Hospital of Varna.

\section{RESULTS}

Graphs on Fig.1A and Fig.1B present well established and stable tendency toward increase of the number of patients with malignant neoplastic diseases, also the number and percentage of the patients at the final IV TNM stage. 
Peev N. A., S. T. Dyankov, Sv. Kalevski ...

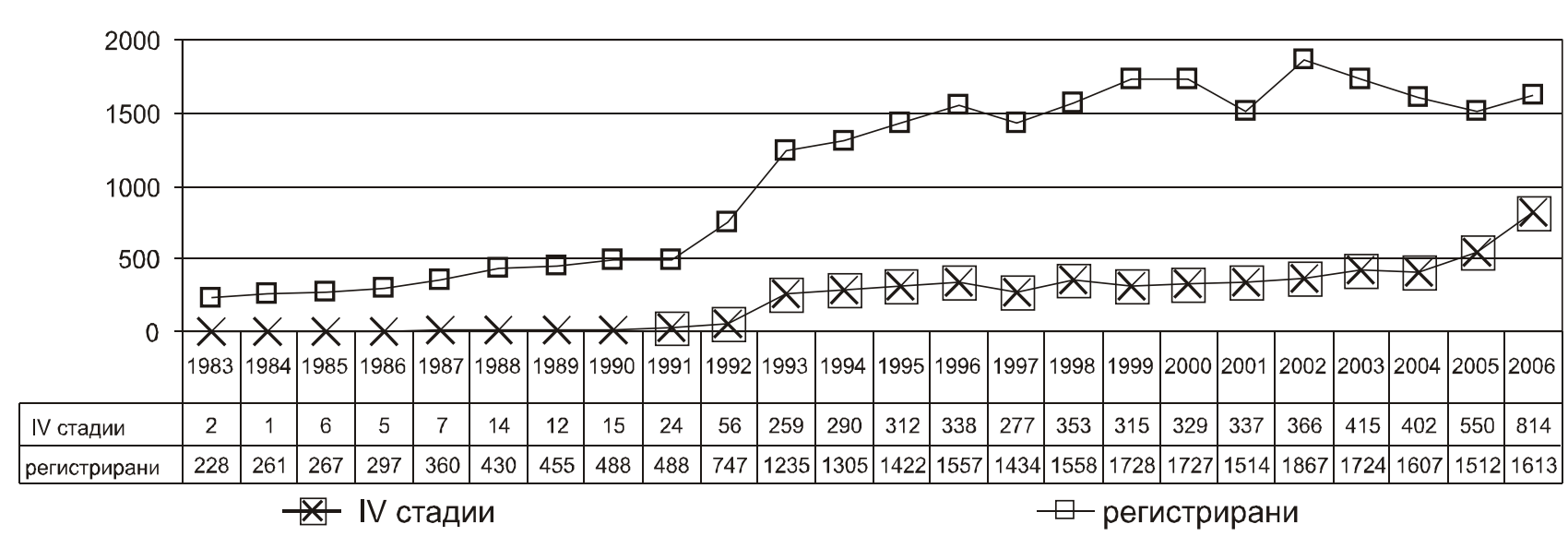

Fig 1A. Patients with malignant neoplastic diseases in Varna region

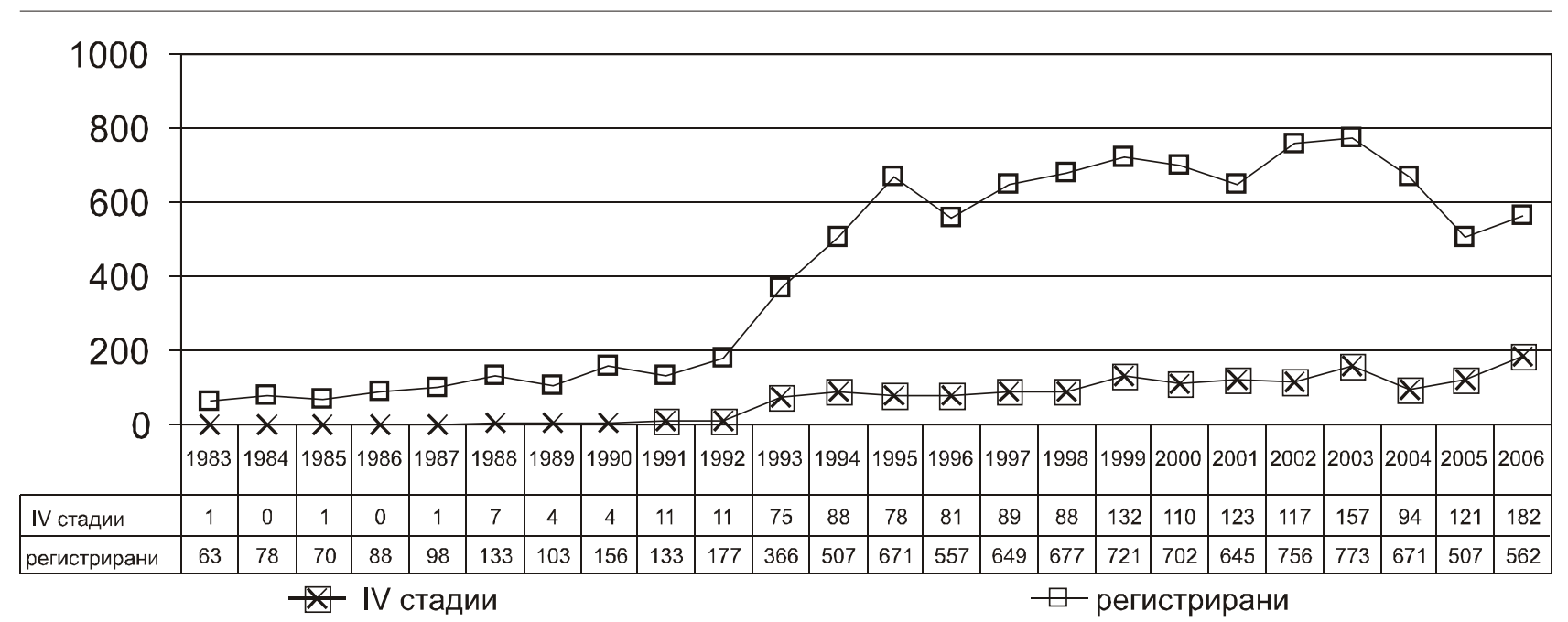

Fig 1B. Patients with malignant neoplastic diseases in Dobrich region

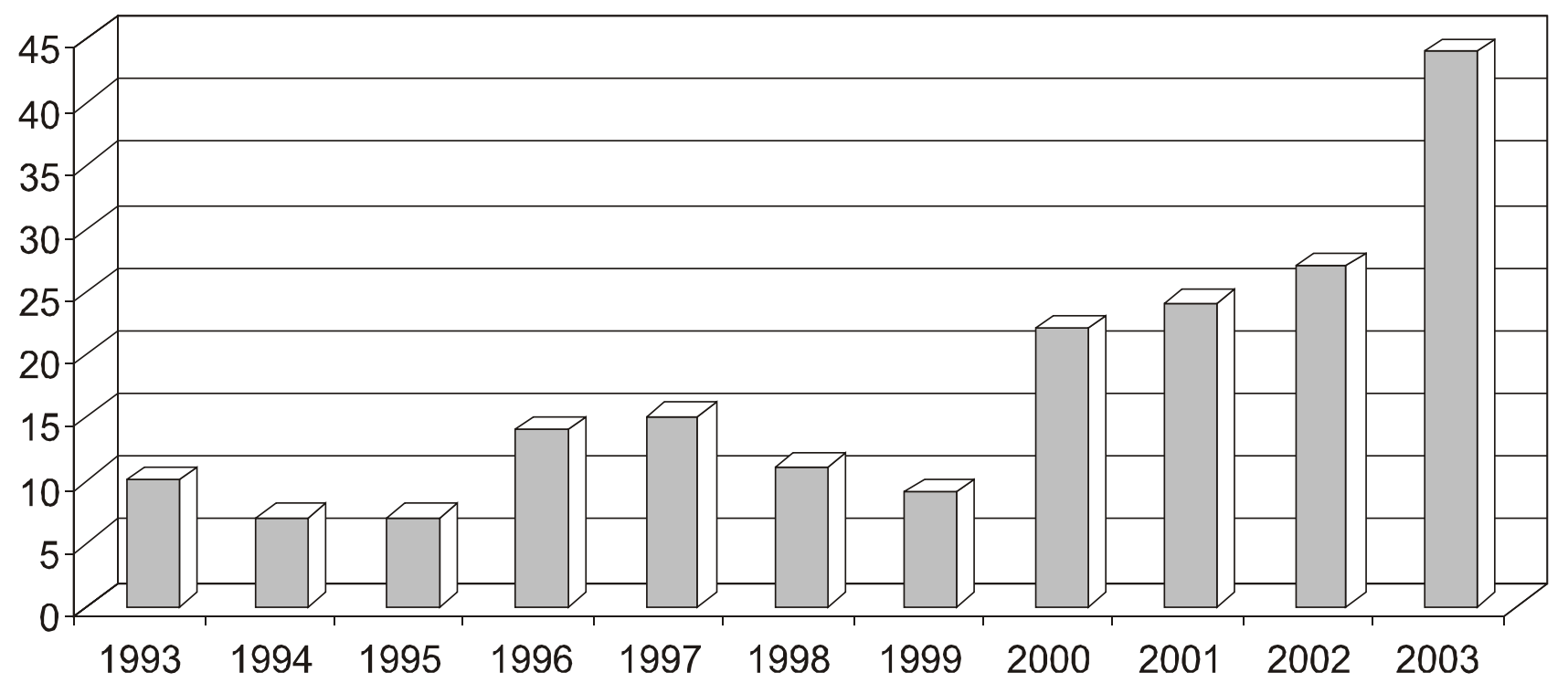

Fig 2. Patients with BMs treated in Neurosurgical clinic of Varna 
Our investigation demonstrates an increase of $54 \%$ for a period of 15 years (1992-2006) in city of Varna and the adjacent region. The established tendencies are with concordance with data for worldwide increase of the number of malignant diseases, presented by other authors that study the same problem.

Graphs on Fig.1A and Fig.1B present well established and stable tendency toward increase of the number of patients with malignant neoplastic diseases, also the number and percentage of the patients at the final IV TNM stage. The graph on Fig. 2 presents tendency towards increase of the patients with BMs.

\section{DISCUSSION}

Above mentioned facts speculate that beside the development of medicine, the incidence of malignancy is constantly increasing. Early started diagnostic and treatment procedures using high techs procedures, makes for the early discovery of brain metastasis and their proper treatment. On the other hand the prolonged survival due to improved treatment of primary tumors, contribute for the increasing number of cases with brain metastasis. According the literature $20-40 \%$ of patients diagnosed with malignant neoplastic disease, have brain metastasis and represent approximately $0,15 \%$ of the population of the planet $(28,19,19,3,18)$.

It's well-known that cases with brain metastasis are considered to be in the final fourth malignancy stage, and the survival is frequently less than a year. So, the problems regarding adequate and optimal treatment of BMs come to be a problem of the present day. The progress attained for their treatment is very important, because of their high incidence and death-rate- almost $100 \%$ (19). They are also one of the most frequent reason causing neurologic complications among patients with malignancies $(31,40,28)$ and are believed to be the most common intracranial tumors. Nowadays investigations report that $1 / 2$ of patients suffer from neoplastic diseases, have also BMs at the same time $(39,9)$. The incidence reported is approximately $12 / 100,000$ per year $(15,32,41)$. As for some of the authors BMs incidence surpass the primary tumors up to ten times $(1,26)$.

According the literature about $30 \%$ of BMs remain asymptomatic and are diagnosed accidentally on CT - scans, MRI or autopsy. [1,5] Beside the aforementioned, $1 / 4$ of patients with BM remain undiagnosed till the autopsy (10).

The accurate incidence of BM is unknown. The values reported from different studies vary in wide ranges. Great number of authors report that the BMs incidence is increasing over last years but, it's not clear yet, if it's due to a real increase.

Progress in medicine contributes to survival of this group of patients. On the other hand the ageing of population inevitably increases the risk of neoplastic diseases, subsequently the risk of BM.

The improved care and treatment for patients that suffer from malignancies contributes for prolonged survival but also for development of symptomatic BM arrising from cells passed through BBB $(20,21,24,38)$.

It's believed that the reason for the increase of BMs could be the improved diagnostic investigations, also the accurate registration of such patients. Yet there are published a few population based studies concerning BMs.

Studies in Europe (Island, Finland) report for BMs rate $2,8-3,4$ per 100,000 people and rate $7,8-12,3$ per 100,000 for primary malignancies $(12,8)$.

Studies in USA during the 70-80's report for a higher incidence $8,2-12,5 / 100,000(25,42)$.

In a study of "the American cancer society" from 1999, the incidence of BMs is vastly higher - between 100,000200,000 diagnosed cases per year and 1/5-1/4 $(112,620-140,775)$ of them diagnosed during autopsy $(16)$. Many authors however, are unanimous that the incidence of BM is underestimated because performing such studies is not easy due to variety of difficulties that interfere in investigations. First of all, there is inadequate registration of patients - usually the patient with diagnosed BMs and primary tumors, are registered according to the primary and clinical stage (TNM), thus the localization of metastasis is not indicated. A matter of great importance is that a large number of metastasis remain asymptomatic and are diagnosed post mortem. Furthermore, primarily in the earlier studies there is a considerable number of patients, that are diagnosed with brain tumor based on neuroimaging, but discharged from the hospitals without histopathological verification.. For example, in Walker's study performed in ' 85 only $20 \%$ of tumors diagnosed as BMs are confirmed histopathologicaly $(36,10,17)$.

Most of studies concerning BMs incidence are based on neurosurgical series.

Series from years 1930-1960 report for 3-10\% incidence of BMs. For the aforementioned period the operative activity regarding BMs was low and these patients were rarely encountered at neurosurgical clinics $(7,34,35)$. From the series investigated in 1960s-1970s a higher incidence of brain metastasis is reported $\sim 10-13 \%(2,23,29)$.

Data reported by Paal \& Bohler -based on the statistical information assembled from 13 pathologic institutes BMs represent $13-40 \%$, materials analyzed from 11 neurologic clinics give 8,5-30,2\% incidence; and from the analyzed data gathered from 18 neurosurgical clinics gained an incidence of $3-10,2 \%(22)$.

Remarkably higher incidence of BM, exceeding the primary tumors is reported from the studies after the' 80 s and especially after the ' 90 s. $(30,27,45)$.

Clinical series of patients treated for brain tumors are another source of information for BM incidence. Factors that cause underestimation of their real incidence are similar to those of population based epidemiologic studies. Usually these studies are based on diagnosis at discharge which could also be inaccurate. Walker reports that $10 \%$ of discharge diagnoses are inexact. Despite of these facts, clinical series confirm, that BM exceed the incidence of primary of brain tumors $(11,14)$. 
Authors followed autopsy series report a higher than in clinical and neurosurgical series incidence of BM (lower for early series and higher for most recent ones). According these data, BMs present in 1/6-1/4 of patients suffered from any malignancy and $2 / 3$ of them have been symptomatic. $(6,37,4)$. It is important to be noted that number of autopsies is continuously decreasing, thus obstructing the process of investigation. In USA, for 2003 only $5 \%$ of died patients were autopsied (33).

\section{CONCLUSION}

The analysis of the literature and data of our study show that despite the progress of medicine, the number of patients suffering from malignancies, respectively the number of patient graded to IV final TNM, is continuously increasing. A great number of patients belonging to IV stage develop neurological complications, mostly BMs. At the present moment it is known that BMs have a higher incidence than primary brain tumors and their number is continuously increasing through the years. So, the adequate treatment of this group of population is an actual problem.

\section{REFERENCE LIST}

1. Arnold SM and Patchell RA. Diagnosis and management of brain metastases. Hematol Oncol Clin North Am. 2001; 15:1086-1107.

2. Arseni $\mathrm{C}$ and Constantinescu AI. Considerations on the metastatic tumors of the brain with reference to a statistics of 1217 cases. Schweiz Arch Neurol Neurochir. 1975; 117:179-195.

3. Bartumeus F and Clavel P. Surgical treatment of brain metastases. Rev Neurol. 2000; 31(12):1247-1249.

4. Cairncross JG, Kim J-H, Posner JB. Radiation therapy of brain metastases. Ann Neurol. 1980; 7:529-541.

5. Cappuzzo F, Mazzoni F, Maestri A, Di Stefano A, Calandri C, Crino L. Medical treatment of brain metastases from solid tumours. Forum (Genova). 2000; 10(2):137-148.

6. Chason JL, Walker FB, Landers JW. Metastatic carcinoma in the central nervous system and dorsal root ganglia: aprospective autopsy study. Cancer. 1963; 16:781-787.

7. Cushing H. Intracranial tumors. Notes upon a Series of Two Thousand Verified Cases with Surgical Mortality Persentages Pertaining Thereto. Springfield, IL, Charles C Thomas, 1932, pp 8 and 105. 1932;

8. Fogelholm R, Uutela T, Murros K. Epidemiology of central nervous system neoplasms. A regional survey in Central Finland. Acta Neurol Scand. 1984; 69:129-136.

9. Gandola L, Navarria P, Lombardi F. Treatment of single brain metastases. Forum (Genova). 2001; 11(1):38-58.

10. Gavrilovic IT and Posner JB. Brain metastases: epidemiology and pathophysiology. $J$ Neurooncol. 2005; 75:5-14.
11. Grant R, Whittle IR, Collie DA. Referral patern and management of patients with malignant brain tumors in South East Scotland. Health Bull (Edinb). 1996; 54:212-222.

12. Guomundsson KR. A survey of tumors of the central nervous system in Iceland during the 10-year period 1954-1963. ActaNeurol Scand. 1970; 46:538-552.

13. Hristova L, Dimova I, Iltcheva M. Projected cancer incidence rates in Bulgaria, 1968 - 2017. International Journal of Epidemiology. 1997; 26(3):469-475

14. Kawahata N and Ohtomo E. Metastatic brain tumors in elderly. Rinsho Shinkeigaku. 1989; 29:1106-1109.

15. Kehrli P. Epidemiology of brain metastases. Neurochirurgie. 1999; 43:357-363.

16. Landis SH, Murray T, Bolden S. Cancer ststistics, 1999. CA Cancer J Clin. 1999; 49:9-31.

17. Lang FF, Chang EL, Abi-Said D, Wildrick DM, Sawaya R. Metastatic Brain Tumors. In: Winn RH (ed) Youmans Neurological Surgery(5ed).Elsevier, New York, pp.1077-1097. 2005;

18. Lohr F, Pirzkall A, Hof H, Fleckenstein K, Debus J. Adjuvant treatment of brain metastases. Semin Surg Oncol. 2001; 20(1):50-56.

19. Massot-Punyet $\mathrm{R}$ and Almajano J. Cerebral metastases. Rev Neurol. 2000; 31(12):1242-1247.

20. Mayer RJ, Berkowitz RS, Griffiths CT. Central nervous system involvement by ovarian carcinoma: a complication of prolonged survival with metastatic disease. Cancer. 1978; 41:776-783.

21. Newlands ES. Chemotherapy for brain metastases. Prog ExpTumor Res. 1985; 21:167-176.

22. Paal G and Bohler M. Zerebrale Metastasen aus klinischer Sicht. Fortchr Neurol Psych. 1969; 3:113-162.

23. Paillas JE and Pellet W. Brain metastases. In: Vinken PJ, Bryun GW (eds) Handbook of Clinical Neurology.New York, Elsevier, pp.201-232. 1975;

24. Paterson AH, Agarwal M, Lees A. Brain metastases in breast cancer patients receiving adjuvant chemotherapy. Cancer. 1982; 41:651-654.

25. Percy AK, Elveback LR, Okazaki H. Neoplasms of the central nervous system: epidemiologic considerations. Neurology. 1972; 22:40-48.

26. Petrovich Z, Yu C, Giannotta SL, O'Day S, Apuzzo MLJ. Survival and pattern of failure in brain metastasis treated with stereotactic gamma knife radiosurgery. J Neurosurg. 2002; 97(Suppl. 5):499-506.

27. Posner JB. Neurological Complications of Cancer, vol 45. Philadelphia, FA Davis, 1995; 1995.

28. Posner JB and Chernik NL. Intracranial metastases from systemic cancer. Adv Neurol. 1978; 19:579-592.

29. Richards $P$ and McKissock W. Intracranial metastases. Br Med J. 1963; 1:15-18.

30. Sawaya R, Hammoud M, Schoppa D. Neurosurgical outcomes in a modern series of 400 craniotomies for treatment of parenchymal brain tumors. Neurosurgery. 1998; 42:1044-1055. 
31. Schiff D. Single brain metastasis. Curr Treat $O p$ tions Neurol. 2001; 3:89-99.

32. Sheehan J, Niranjan A, Flickinger J, Kondziolka K, Lunsford D. The expanding role of neurosurgeons in the management of brain metastases. Surg Neurol. 2004; 62:32-41.

33. Shojania KG, Burton EC, McDonald KM, Goldman L. Changes in rates of autopsy-detected diagnostic errors over time: a systematic review. JAMA. 2003; 289:2849-2856.

34. Simonescu MD. Metastatic tumors of the brain: a follow-up study of 195 patients with neurosurgical considerations. J Neurosurg. 1960; 17:361-373.

35. Stortebecker TR. Metastatic tumors of the brain from a neurosurgical point of view. A follow-up study of 158 cases. J Neurosurg. 1954; 11:84-111.

36. Suki D. The epidemiology of brain metastases. In: Sawaya R (ed) Intracranial metastases.Current management strategies.Blackwell, Futura, pp.21-34. 2004;

37. Takakura K, Sano K, Hojo S. Metastatic Tumors of the Central Nervous System. Tokio, Igaku-Shoin, 1982, pp.5-35. 1982;
38. Thomas AJ, Rock JP, Johnson CC, Weiss L, Jacobsen G, Rosenblum ML. Survival of patients with synchronous brain metastases: an epidemiological study in southeastern Michigan. J Neurosurg. 2000; 93:927-931.

39. Tsao IN and Wong RKS. Clinical practice guideline on the optimal radiotherapeutic management of brain metastases. BMC Cancer. 2005; 5:34-41.

40. Van den Bent MJ. The diagnosis and management of brain metastases. Curr Opin Neurol. 2001; 14:717-723.

41. Vecht CJ. Clinical management of brain metastasis. J Neurol. 1998; 245:127-131.

42. Walker AE, Robins M, Weinfeld FD. Epidemiology of brain tumors: the national survey of intracranial neoplasms. Neurology. 1985; 35:219-226.

43. WHO. Fact sheet No297 February 2006. 2006;

44. WHO. World health statistics 2006. 2006;

45. Wingo PA, Tong T, Bolden S. Cancer ststistics, 1995. CA Cancer J Clin. 1995; 45:8-30. 